\title{
Symptoms of postpartum anxiety and depression among women in Canada: findings from a national cross-sectional survey
}

\author{
Mihaela Gheorghe ${ }^{1}$ (1) $\cdot$ Mélanie Varin ${ }^{1} \cdot$ Suzy L. Wong ${ }^{1} \cdot$ Melissa Baker ${ }^{1} \cdot$ Vera Grywacheski $^{1} \cdot$ Heather Orpana ${ }^{1,2,3}$
}

Received: 7 May 2020 / Accepted: 14 September 2020 / Published online: 20 October 2020

(C) The Author(s) 2020

\begin{abstract}
Objective This study presents national estimates on symptoms consistent with postpartum anxiety (PPA) and postpartum depression (PPD) and the association between these conditions and possible risk and protective factors in women who gave birth in Canada.

Methods Data were collected through the Survey on Maternal Health, a cross-sectional survey administered in Canada's ten provinces between November 2018 and February 2019 among women who gave birth between January 1 and June 30, 2018. A total of 6558 respondents were included. Weighted prevalence estimates were calculated, and logistic regression was used to model the relationship between symptoms consistent with PPA, PPD, and potential risk factors.

Results Overall, $13.8 \%$ of women had symptoms consistent with PPA, while the prevalence of having symptoms consistent with PPD was $17.9 \%$. Results of the logistic regression models indicated that women who had a history of depression were 3.4 times (95\% CI 2.7-4.2) more likely to experience symptoms consistent with PPA and 2.6 times more likely to experience symptoms consistent with PPD (95\% CI 2.2-3.2) compared with those who did not. Women who reported good, fair, or poor physical health were 2.4 times more likely to experience symptoms consistent with PPD (95\% CI 2.0-2.9) and 2.0 times more likely to experience symptoms consistent with PPA (95\% CI 1.7-2.4) compared with those who reported very good or excellent health. Maternal marital status, other postpartum maternal support, and sense of community belonging were also significant.

Conclusion This study highlights that a history of depression and good, fair, or poor physical health are associated with an increased odds of symptoms consistent with PPA and PPD, while other maternal support and sense of community belonging are associated with a decreased odds of these conditions.
\end{abstract}

\section{Résumé}

Objectif La présente étude présente des estimations nationales sur les symptômes correspondant à de l'anxiété post-partum (APP) et à une dépression post-partum (DPP) et sur l'association entre ces affections et les éventuels facteurs de risque et de protection chez les femmes ayant accouché au Canada.

Méthodologie Les données ont été recueillies dans le cadre de l'Enquête sur la santé maternelle, une enquête transversale menée dans les dix provinces canadiennes entre novembre 2018 et février 2019 auprès des femmes ayant accouché entre le $1^{\text {er }}$ janvier et le 30 juin 2018. Au total, 6558 personnes ont répondu à l'enquête. Des estimations de la prévalence pondérée ont été calculées, et une régression logistique a été utilisée pour modéliser la relation entre les symptômes correspondant à de l'APP, à une DPP et aux facteurs de risque possibles.

Résultats Dans l'ensemble, 13,8\% des femmes présentaient des symptômes compatibles avec de l'APP, tandis que la prévalence des symptômes compatibles avec une DPP était de 17,9\%. Les résultats des modèles de régression logistique ont indiqué que les femmes ayant des antécédents de dépression étaient 3,4 fois (IC à $95 \%: 2,7$ à 4,2) plus susceptibles de présenter des symptômes compatibles avec de l'APP et 2,6 fois plus susceptibles de présenter des symptômes compatibles avec une DPP (IC à $95 \%: 2,2$ à $3,2)$ par rapport à celles qui n'en avaient pas. Les femmes qui ont déclaré être en bonne, moyenne ou mauvaise santé physique

Mihaela Gheorghe

mihaela.gheorghe@canada.ca

1 Public Health Agency of Canada, 785 Carling Avenue, Ottawa, ON K1S 5H4, Canada
2 School of Epidemiology and Public Health, University of Ottawa, Alta Vista Campus, Room 101, 600 Peter Morand Crescent, Ottawa, ON K1G 5Z3, Canada

3 Royal Ottawa Institute for Mental Health Research, 1145 Carling Ave, Ottawa, ON K1Z 7K4, Canada 
étaient 2,4 fois plus susceptibles d'éprouver des symptômes correspondant à une DPP (IC à $95 \%: 2,0$ à 2,9) et 2,0 fois plus susceptibles d'éprouver des symptômes correspondant à de l'APP (IC à $95 \%: 1,7$ à 2,4) par rapport à celles qui ont déclaré être en très bonne ou en excellente santé. L'état matrimonial de la mère, les autres formes de soutien maternel post-partum et le sentiment d'appartenance à la collectivité étaient également significatifs.

Conclusion Cette étude souligne que des antécédents de dépression et une bonne, moyenne ou mauvaise santé physique sont associés à une augmentation de la probabilité de symptômes correspondant à de l'APP et à une DPP, tandis que d'autres formes de soutien maternel et le sentiment d'appartenance à la collectivité sont associés à une diminution de la probabilité de ces affections.

Keywords Maternal health $\cdot$ Mental health $\cdot$ Postpartum depression $\cdot$ Postpartum anxiety disorder $\cdot$ Pregnancy

Mots-clés Santé maternelle $\cdot$ santé mentale $\cdot$ dépression post-partum · anxiété post-partum · grossesse

\section{Introduction}

Following childbirth, mothers may experience a range of emotions, including deep sadness or worrying, which can appear within days and last for years if left undiagnosed (Lanes et al. 2011; Pawluski et al. 2017). Approximately 6-13\% of women in developed countries report symptoms consistent with postpartum depression (PPD), while estimates of postpartum anxiety (PPA) range more widely, from 13 to $40 \%$ (Field 2018). More recently, Shoreya et al. (2018) estimated the prevalence of PPD at $17 \%$ globally. These conditions often remain undiagnosed and untreated in part because some of the associated symptoms, such as fatigue, weight fluctuation, or sleep disturbance, may be expected during the postpartum period (Iliadis et al. 2018). In addition to these more generalized symptoms, PPA may also be characterized by excessive worrying and obsessing, while PPD manifests as long-lasting and potentially severe feelings of sadness and hopelessness (Iliadis et al. 2018). PPD is often comorbid with PPA and symptomology is associated with greater severity (Pawluski et al. 2017; Ramakrishna et al. 2019). The strongest predictors of PPD include: depression during pregnancy, anxiety during pregnancy, experiencing stressful life events during pregnancy or the early puerperium, low levels of social support, and a previous history of depression (Robertson et al. 2004).

PPD may have immediate effects on the mother, such as impaired ability to cope with life events and parenting tasks (Brummelte and Galea 2016). The condition may also have a negative impact on the mother-infant attachment, sensitivity to her child, and family functioning, which can create lasting effects on the child's brain development and reaction to stress (Brummelte and Galea 2016). Similarly, PPD may affect the health of other children in the family and the partner relationship.

The last national survey to measure PPD in Canada was the Maternity Experiences Survey, which was conducted in 2006 (PHAC 2009). There are currently no national estimates of symptoms consistent with PPA. The main objectives of this study were to present the first national estimates on symptoms consistent with postpartum anxiety, to provide updated estimates of symptoms consistent with postpartum depression, and to describe characteristics of women who gave birth in Canada between January 1 and June 30, 2018. The secondary objective of this study was to report on the association between these conditions and possible risks and protective factors during pregnancy and postpartum.

\section{Methods}

Data were extracted from the Survey on Maternal Health $(\mathrm{SMH})$, which was administered from November 29, 2018 to February 5, 2019. The Child Tax Benefit registry was used as the sampling frame to identify women who had given birth between January 1 and June 30, 2018, and included women five to thirteen months postpartum. The target sample included 13,000 dwellings in the ten provinces. Data were collected from 7085 women (54.7\% response rate). Of these women, $6558(92.6 \%)$ agreed to share their responses with the Public Health Agency of Canada (PHAC). All women who agreed to share their responses were included in the study. Of these, 4676 completed an electronic questionnaire and 2409 completed the survey by computer-assisted telephone interview. To ensure confidentiality and protection of privacy, data collected in this survey were under the authority of the Statistics Act.

\section{Survey content}

Symptoms consistent with postpartum depression were measured through the 5-item version of the Edinburgh Postpartum Depression Scale (EPDS-5) (Eberhard-Gran et al. 2007). Women who scored 7 or above were considered to have a moderate symptom level of PPD in the seven days prior to completing the survey. The EPDS-5 correlates well with the full EPDS $(r=0.96)$ and demonstrated a Cronbach's alpha of 
0.76. Symptoms consistent with generalized anxiety symptoms were measured through the 2-item Generalized Anxiety Disorder scale (GAD-2) (Nath et al. 2018; Kroenke et al. 2007). The GAD-2 has demonstrated a sensitivity of $69 \%$ and a specificity of $91 \%$ with GAD diagnosed using the Structured Clinical Interview for the DSM-IV. Women who scored 3 or above were considered to have symptoms consistent with generalized anxiety disorder in the two weeks prior to completing the survey. It is important to note that these tools may only be used to screen for symptoms consistent with PPA or PPD, and are not intended to replace clinical diagnosis.

\section{Socio-demographic factors}

Socio-demographic characteristics, such as age (continuous and by age group), were presented in the analysis. Additional characteristics included education level: "What is the highest certificate, diploma or degree that you have completed?" (measured as "less than high school", "high school graduate", or "post-secondary graduate") and marital status: "What is your marital status?" (measured as "married/common law" or "never married/separated/divorced" or "widowed").

\section{Maternal support and sense of belonging}

Three concepts are measured in this section: maternal support programs, other maternal support, and sense of belonging to the community. Questions related to maternal support programs included: "During your pregnancy with [your child], did you attend pregnancy support programs? For example, programs where you learned about having a healthy pregnancy or caring for your baby." (Yes/No); and "Since the birth of your baby, did you attend any parenting support programs? For example, programs where you learn about caring for your child, breastfeeding support, parenting skills and infant or child development" (Yes/No). Other maternal support was measured by the question, "Since the birth of your baby, when you needed other support, how often was it available?" (analyzed as "all or most of the time" or "some, a little or none of the time"). Respondents were also asked "How would you describe your sense of belonging to your local community?" (measured as "strong", "very strong" or "somewhat weak", "very weak"), which we refer to as sense of belonging.

\section{History of depression and treatment}

Questions regarding history of depression or a mood disorder, and treatment were also analyzed for this study, including: "Has a doctor, midwife, nurse or other health care worker ever told you that you had depression or a mood disorder?" (measured as "Yes, before you were pregnant with [your child]",
"Yes, while you were pregnant with [your child]", "Yes, since the birth of [your child]", "No."). Women were also asked if they received mental health care: "Since the birth of your baby, have you received treatment for your emotions or mental health?" (measured as "Yes, medication, such as antidepressants", "Yes, counselling, such as talk therapy"; "Yes, medication and counselling"; "No.").

\section{Self-reported mental health, general health, and life satisfaction}

Respondents were asked: "Since the birth of your baby, did you ever feel so sad, miserable or anxious that you were concerned about your emotions or mental health?"; "At these times, when you were concerned about your emotions or mental health, did you talk to anyone? [Select all that apply]"; "Was it: 1: Family doctor, midwife, or nurse; 2: Psychiatrist, psychologist, social worker, or counsellor; 3: Spouse or partner; 4: Family or friend; 5: Someone else."

Respondents were asked "In general, how would you rate your physical health?" and "In general, how would you rate your mental health?" (both measured as "excellent", "very good" or "good", "poor" or "fair.")

In order to assess life satisfaction, respondents were asked: "Using a scale of 0 to 10 , where 0 means "Very dissatisfied" and 10 means "Very satisfied", how do you feel about your life as a whole right now?"

\section{Analysis}

Descriptive analyses were conducted for women with symptoms consistent with PPA and PPD, as well as those who did not experience symptoms consistent with either condition, as a reference category. Weighted proportions, means, and 95\% confidence intervals (CI) were presented to provide national estimates. CIs were calculated using the bootstrap method (with 1000 replications), in order to account for the complex sampling design.

Two logistic regression models were used to examine the relationship between PPA and PPD, separately, with socio-demographic factors, maternal support programs, availability of other types of support, sense of belonging, history of depression, and self-rated physical health. Analyses were conducted in SAS EG 5.1 (SAS Institute Inc., Cary, NC, USA). Cases with missing data on a variable were excluded from analyses which used that variable. The primary null hypothesis of our multiple logistic regression models was that there is no relationship between the potential risk factors selected and the incidence of PPA or PPD. 


\section{Results}

Overall, $13.8 \%$ of women who gave birth in Canada between January 1 and June 30, 2018 had symptoms consistent with PPA, while the prevalence of symptoms consistent with PPD was $17.9 \%$.

\section{Unadjusted results}

Descriptive characteristics of women who had symptoms consistent with PPA, PPD, or neither condition are outlined in Table 1. The largest proportion of women with symptoms consistent with PPA or PPD were in the 25-29 and 30-35 age groups, were married or in a common-law relationship, and had a post-secondary education. These associations were similar to women who did not experience symptoms consistent with either condition.

More than three quarters of women with symptoms consistent with PPA (76.4\%) and $82.0 \%$ of women with symptoms consistent with PPD rated their mental health as being "poor", "fair", or "very good", which is considerably higher than those who did not have symptoms consistent with either condition $(30.0 \%)$. With regard to physical health, $64.5 \%$ of women with symptoms consistent with PPD rated their physical health as "poor", "fair", or "good", which is notably higher than women with symptoms consistent with PPA $(37.6 \%)$ or those who did not have symptoms consistent with either condition $(34.5 \%)$.

A smaller proportion of women who had symptoms consistent with PPA and PPD, 55.3\% and 53.9\%, respectively, felt that they had a strong sense of community belonging and had other postpartum support available all or most of the time compared with women who did not have symptoms consistent with either condition (79.8\%). Prevalence estimates for the use of pregnancy support programs and parenting support programs were similar in all three groups examined (i.e., PPA, PPD, or neither condition).

Of those who ever had a history of depression or a mood disorder, and who had symptoms consistent with PPD at the time they completed the survey, $41.8 \%$ had received no treatment since the birth of their baby; $25.2 \%$ had been treated with medication, such as antidepressants; $18.4 \%$ had counselling, such as talk therapy; and $14.7 \%$ had been treated with both medication and counselling. Similar proportions were reported in women who had symptoms consistent with PPA.

Among women who had symptoms consistent with PPD or PPA, $71.6 \%$ and $68.2 \%$, respectively, reported being concerned about their emotions or mental health, which is substantially higher than those who did not have symptoms consistent with either disorder (23.0\%). More than eight out of ten women who had symptoms consistent with PPA $(81.4 \%)$ or PPD $(81.2 \%)$ and were concerned about their emotions or mental health spoke to someone about it, which is slightly lower than women who did not have symptoms consistent with either condition who had concerns about their emotions or mental health $(89.0 \%)$.

Of those who spoke to someone and had symptoms consistent with PPD, $47.9 \%$ spoke to a family doctor, midwife, or nurse; $30.6 \%$ spoke to a psychiatrist, psychologist, social worker, or counsellor; $70.0 \%$ spoke to their spouse or partner; $71.0 \%$ spoke to their family or a friend; and $7.9 \%$ spoke to someone else. These estimates were similar for women who had symptoms consistent with PPA.

The chi-square tests indicated that all variables studied were significantly associated with PPA and PPD, with the exception of pregnancy support programs and talking to "family or friend" or "someone else" when concerned about mental health.

\section{Adjusted results}

The association between socio-demographic factors, social factors, history of depression or a mood disorder, and selfrated physical health and PPA and PPD are presented in Table 2.

The logistic regression models showed that women who had a history of depression were 3.4 times (95\% CI 2.7-4.2) more likely to experience PPA and 2.6 times more likely to experience PPD (95\% CI 2.2-3.2) compared with women who did not. Women who reported good, fair, or poor physical health were 2.4 times more likely to experience PPD $(95 \%$ CI 2.0-2.9) and 2.0 times more likely to experience PPA (95\% CI 1.7-2.4) compared with those who reported having very good or excellent health. Women who reported a somewhat or very weak sense of belonging to local community were more likely to experience PPA (aOR 2.1, 95\% CI 1.7-2.5) and PPD (aOR 2.4, 95\% CI 2.0-2.8) compared with those who reported having a very strong or somewhat strong sense of belonging. Finally, women who were never married, or were separated, divorced, or widowed had significantly higher odds of PPA (aOR 1.6, 95\% CI 1.2-2.3) and PPD (aOR 1.5, 95\% CI 1.12.1) compared with women who were married or common law. Age, education, and attending pregnancy support programs were not significantly associated with PPA and PPD.

\section{Discussion}

We found that approximately one in four women who gave birth in Canada between January 1 and June 30, 2018 reported symptoms consistent with PPA or PPD five to thirteen months postpartum. This is comparable with estimates reported by the United States (US) Centers for Disease Control and Prevention (CDC), where up to one in five women are estimated to experience symptoms of PPD in some states (CDC 2020). Historically, the first national PPD estimates were 
Table 1 Descriptive characteristics of women who had symptoms consistent with PPA, PPD, or neither condition

\begin{tabular}{|c|c|c|c|c|c|c|c|c|c|}
\hline \multirow{3}{*}{$\begin{array}{l}\text { Variable } \\
\text { Age category }\end{array}$} & \multicolumn{3}{|l|}{ PPA } & \multicolumn{3}{|l|}{ PPD } & \multicolumn{3}{|c|}{ Neither condition } \\
\hline & \multirow{2}{*}{$\begin{array}{l}\text { Percent } \\
n=882^{*}\end{array}$} & \multicolumn{2}{|c|}{$\begin{array}{l}95 \% \text { confidence } \\
\text { limits }\end{array}$} & \multirow{2}{*}{$\begin{array}{l}\text { Percent } \\
n=113\end{array}$} & \multicolumn{2}{|c|}{$\begin{array}{l}95 \% \text { confidence } \\
\text { limits }\end{array}$} & \multirow{2}{*}{$\begin{array}{l}\text { Percen } \\
n=50\end{array}$} & \multicolumn{2}{|c|}{$\begin{array}{l}95 \% \text { confidence } \\
\text { limits }\end{array}$} \\
\hline & & & & & & & & & \\
\hline $17-24$ & 10.4 & 7.7 & 13.0 & 10.6 & 8.2 & 13.0 & 7.1 & 6.2 & 8.0 \\
\hline $25-29$ & 27.9 & 24.2 & 31.6 & 24.8 & 21.6 & 28.1 & 24.0 & 22.6 & 25.4 \\
\hline $30-34$ & 37.0 & 32.9 & 41.0 & 37.7 & 34.3 & 41.1 & 38.5 & 36.9 & 40.1 \\
\hline $35-39$ & 19.3 & 16.2 & 22.4 & 21.2 & 18.4 & 24.0 & 23.8 & 22.3 & 25.2 \\
\hline $40+$ & 5.5 & 3.8 & 7.3 & 5.6 & 4.0 & 7.2 & 6.7 & 5.8 & 7.5 \\
\hline Marital status & \multicolumn{3}{|c|}{$n=888^{*}$} & \multicolumn{3}{|c|}{$n=1138^{*}$} & \multicolumn{3}{|c|}{$n=5066$} \\
\hline Married/common law & 83.1 & 79.8 & 86.5 & 84.5 & 81.6 & 87.4 & 92.0 & 91.0 & 93.0 \\
\hline Not married & 16.9 & 13.5 & 20.2 & 15.5 & 12.6 & 18.4 & 8.0 & 7.0 & 9.0 \\
\hline Education level & \multicolumn{3}{|c|}{$n=885^{*}$} & \multicolumn{3}{|c|}{$n=1135^{*}$} & \multicolumn{3}{|c|}{$n=5063$} \\
\hline Less than high school & 9.2 & 6.6 & 11.8 & 8.3 & 6.2 & 10.5 & 5.6 & 4.7 & 6.4 \\
\hline High school graduate & 18.4 & 15.1 & 21.6 & 19.5 & 16.5 & 22.4 & 16.2 & 14.9 & 17.5 \\
\hline Post-secondary graduate & 72.4 & 68.7 & 76.2 & 72.2 & 68.9 & 75.6 & 78.2 & 76.8 & 79.7 \\
\hline Self-reported mental health & \multicolumn{3}{|c|}{$n=887^{*}$} & \multicolumn{3}{|c|}{$n=1134 *$} & \multicolumn{3}{|c|}{$n=5046$} \\
\hline Poor, fair, or good & 76.4 & 73.0 & 79.8 & 82.0 & 79.1 & 84.9 & 30.0 & 28.4 & 31.6 \\
\hline Very good or excellent & 23.6 & 20.2 & 27.0 & 18.0 & 15.1 & 20.9 & 70.0 & 68.4 & 71.6 \\
\hline Self-reported physical health & \multicolumn{3}{|c|}{$n=887 *$} & $n=1$ & & & $n=5$ & & \\
\hline Poor, fair, or good & 37.6 & 36.1 & 39.1 & 64.5 & 61.1 & 68.0 & 34.5 & 33.0 & 36.1 \\
\hline Very good or excellent & 62.4 & 60.9 & 63.9 & 35.5 & 32.0 & 38.9 & 65.5 & 63.9 & 67.0 \\
\hline Life satisfaction & $n=886$ & & & $n=1$ & & & $n=5$ & & \\
\hline Low & 69.2 & 65.8 & 72.6 & 62.2 & 58.4 & 66.0 & 20.2 & 18.8 & 21.6 \\
\hline High & 30.8 & 27.4 & 34.2 & 37.8 & 34.0 & 41.6 & 79.8 & 78.4 & 81.2 \\
\hline Sense of community belonging & $n=881$ & & & $n=1$ & & & $n=5$ & & \\
\hline Somewhat weak, very weak & 44.7 & 40.6 & 48.7 & 46.1 & 42.4 & 49.9 & 20.2 & 18.9 & 21.5 \\
\hline Very strong, somewhat strong & 55.3 & 51.3 & 59.4 & 53.9 & 50.1 & 57.6 & 79.8 & 78.5 & 81.1 \\
\hline Availability of other types of support since birth of baby & $n=881$ & & & $n=1$ & & & $n=5($ & & \\
\hline All/most of the time & 48.3 & 44.1 & 52.5 & 53.2 & 49.5 & 56.9 & 35.4 & 33.9 & 37.0 \\
\hline Some/little/none of the time & 51.7 & 47.5 & 55.9 & 46.8 & 43.1 & 50.5 & 64.6 & 63.0 & 66.1 \\
\hline Pregnancy support program & $n=888$ & & & $n=1$ & & & $n=5$ & & \\
\hline Yes & 22.5 & 19.2 & 25.9 & 23.7 & 20.8 & 26.6 & 22.4 & 21.1 & 23.8 \\
\hline No & 77.5 & 74.1 & 80.8 & 76.3 & 73.4 & 79.2 & 77.6 & 76.2 & 78.9 \\
\hline Parenting support program & $n=888$ & & & $n=1$ & & & $n=5$ & & \\
\hline Yes & 34.7 & 30.9 & 38.6 & 33.8 & 30.3 & 37.4 & 29.1 & 27.6 & 30.6 \\
\hline No & 65.3 & 61.4 & 69.1 & 66.2 & 62.6 & 69.7 & 70.9 & 69.4 & 72.4 \\
\hline Concerned about mental health & $n=888$ & & & $n=1$ & & & $n=5$ & & \\
\hline Yes & 68.2 & 64.3 & 72.1 & 71.6 & 68.3 & 74.9 & 23.0 & 21.6 & 24.4 \\
\hline No & 31.8 & 27.9 & 35.7 & 28.4 & 25.1 & 31.7 & 77.0 & 75.6 & 78.4 \\
\hline Talked to someone & $n=623$ & & & $n=82$ & & & $n=12$ & & \\
\hline Yes & 81.4 & 77.6 & 85.1 & 81.2 & 77.9 & 84.5 & 89.0 & 86.9 & 91.1 \\
\hline No & 18.6 & 14.9 & 22.4 & 18.8 & 15.5 & 22.1 & 11.0 & 8.9 & 13.1 \\
\hline Family doctor, midwife, or nurse & $n=504$ & & & $n=6$ & & & $n=10$ & & \\
\hline Yes & 49.9 & 44.4 & 55.4 & 47.9 & 42.9 & 52.8 & 41.4 & 37.7 & 45.0 \\
\hline No & 50.1 & 44.6 & 55.6 & 52.1 & 47.2 & 57.1 & 58.6 & 55.0 & 62.3 \\
\hline Psychiatrist, psychologist, social worker, or counsellor & $n=504$ & & & $n=6$ & & & $n=1$ & & \\
\hline Yes & 31.2 & 26.0 & 36.3 & 30.6 & 26.1 & 35.2 & 20.5 & 17.6 & 23.5 \\
\hline No & 68.8 & 63.7 & 74.0 & 69.4 & 64.8 & 73.9 & 79.5 & 76.5 & 82.4 \\
\hline
\end{tabular}


Table 1 (continued)

\begin{tabular}{|c|c|c|c|c|c|c|c|c|c|}
\hline \multirow[t]{2}{*}{ Variable } & \multicolumn{3}{|l|}{ PPA } & \multicolumn{3}{|l|}{ PPD } & \multicolumn{3}{|c|}{ Neither condition } \\
\hline & Percent & $\begin{array}{l}95 \% \\
\text { limits }\end{array}$ & idence & Percent & $\begin{array}{l}95 \% \\
\text { limits }\end{array}$ & idence & Percent & $\begin{array}{l}95 \% \\
\text { limits }\end{array}$ & idence \\
\hline Spouse or partner & \multicolumn{3}{|c|}{$n=504^{*}$} & \multicolumn{3}{|c|}{$n=658^{*}$} & \multicolumn{3}{|c|}{$n=1066$} \\
\hline Yes & 70.5 & 65.0 & 75.9 & 70.0 & 65.5 & 74.5 & 80.6 & 77.5 & 83.7 \\
\hline No & 29.5 & 24.1 & 35.0 & 30.0 & 25.5 & 34.5 & 19.4 & 16.3 & 22.5 \\
\hline Family or friend & \multicolumn{3}{|l|}{$n=504$} & \multicolumn{3}{|l|}{$n=658$} & \multicolumn{3}{|c|}{$n=1066$} \\
\hline Yes & 72.1 & 66.9 & 77.2 & 71.0 & 66.6 & 75.4 & 75.9 & 72.9 & 78.9 \\
\hline No & 27.9 & 22.8 & 33.1 & 29.0 & 24.6 & 33.4 & 24.1 & 21.1 & 27.1 \\
\hline Someone else & \multicolumn{3}{|l|}{$n=504$} & \multicolumn{3}{|l|}{$n=658$} & \multicolumn{3}{|c|}{$n=1066$} \\
\hline Yes & 7.7 & 4.7 & 10.7 & 7.9 & 5.4 & 10.5 & 4.6 & 2.9 & 6.2 \\
\hline No & 92.3 & 89.3 & 95.3 & 92.1 & 89.5 & 94.6 & 95.4 & 93.8 & 97.1 \\
\hline History of depression or a mood disorder (ever) & \multicolumn{3}{|c|}{$n=885^{*}$} & \multicolumn{3}{|c|}{$n=1136^{*}$} & \multicolumn{3}{|c|}{$n=5068$} \\
\hline Yes & 37.1 & 33.2 & 41.0 & 31.7 & 28.4 & 35.0 & 11.2 & 10.2 & 12.2 \\
\hline No & 62.9 & 59.0 & 66.8 & 68.3 & 65.0 & 71.6 & 88.8 & 87.8 & 89.8 \\
\hline $\begin{array}{l}\text { Treatment since birth of baby in women with } \\
\text { a history of depression }\end{array}$ & \multicolumn{3}{|c|}{$n=330^{*}$} & \multicolumn{3}{|c|}{$n=364^{*}$} & \multicolumn{3}{|l|}{$n=600$} \\
\hline No treatment & 40.7 & 33.9 & 47.5 & 41.8 & 35.3 & 48.2 & 55.8 & 50.9 & 60.6 \\
\hline Medication & 23.7 & 17.8 & 29.5 & 25.2 & 19.4 & 31.0 & 23.6 & 19.8 & 27.4 \\
\hline Counselling & 17.6 & 12.2 & 23.0 & 18.4 & 13.4 & 23.4 & 9.7 & 6.8 & 12.6 \\
\hline Medication and counselling & 18.0 & 13.0 & 23.0 & 14.7 & 10.2 & 19.2 & 10.9 & 7.8 & 14.0 \\
\hline
\end{tabular}

*Significant chi-square test with $p<0.05$

measured in Canada through the Maternal Experiences Survey (MES) in 2006 (PHAC 2009). The results of this survey indicated that $7.5 \%$ of women reported having symptoms consistent with depression during the postpartum period; however, due to differences in survey design, including the use of different screening tools, the results of the SMH are not directly comparable with those of the MES. The higher estimates observed in our study may be explained in part by increased mental health awareness in Canada in the last decade, which may have contributed to the respondents' ability to identify and report on symptoms specific to PPA or PPD. Further, unlike for the MES, where responses were collected by a human interviewer, responses to the SMH were largely collected through an online questionnaire. This allows for greater disclosure of symptoms of psychological distress than traditional interviewing methods, which involve a human interviewer, and may have contributed, to some extent, to the higher estimates observed (Milton et al. 2017; Duffy et al. 2005).

\section{Socio-demographic factors}

Marital status was a significant predictor of PPA and PPD in this study. Women who were never married, or were separated, divorced, or widowed were more likely to report symptoms consistent with PPA or PPD. While being married or in a relationship may present certain advantages, it is ultimately the quality of the relationship which contributes to a woman's well-being during the postpartum period, as demonstrated in two meta-analyses (Yim et al. 2015; O'Hara and Swain 1996). The SMH did not collect any information related to the quality of the relationship, which is a limitation of this study.

\section{History of depression and treatment}

Similar to a meta-analysis conducted by Yim et al., having a history of depression was one of the strongest predictors of PPD. This study also showed that among women who had ever been told that they had depression or a mood disorder, the greatest proportion received no treatment, followed by receiving treatment with medication, treatment with counselling, and finally, treatment with both medication and counselling.

Treatment for PPA or PPD varies based on the severity of symptoms and the level of functional impairment. When diagnosed, PPD is considered to be a major depressive disorder, which is typically treated with antidepressants (Sharma and Sharma 2012). Psychotherapy may also have good results either alone or combined with antidepressants for severe depression. For mild or moderate cases of depression or anxiety, the recommended treatment is psychological treatment, or 
Table 2 Association between socio-demographic factors, social factors, history of depression or a mood disorder, and self-rated physical health and PPA or PPD

\begin{tabular}{|c|c|c|c|c|c|c|}
\hline \multirow{3}{*}{$\begin{array}{l}\text { Variable } \\
\text { Age }\end{array}$} & \multicolumn{3}{|c|}{ aOR PPA, 95\% CI } & \multicolumn{3}{|c|}{ aOR PPD, 95\% CI } \\
\hline & \multirow{2}{*}{$\begin{array}{l}\text { Point estimate } \\
1.0\end{array}$} & \multicolumn{2}{|c|}{ 95\% Wald confidence limits } & \multirow{2}{*}{$\begin{array}{l}\text { Point estimate } \\
1.0\end{array}$} & \multicolumn{2}{|c|}{$95 \%$ Wald confidence limits } \\
\hline & & 1.0 & 1.0 & & 1.0 & 1.0 \\
\hline \multicolumn{7}{|l|}{ Education attainment } \\
\hline Less than high school & 0.9 & 0.7 & 1.2 & 1.2 & 1.0 & 1.6 \\
\hline High school graduate & 1.3 & 0.9 & 2.0 & 1.4 & 0.9 & 2.0 \\
\hline Post-secondary graduate & Ref & & & Ref & & \\
\hline \multicolumn{7}{|l|}{ Marital status } \\
\hline Married/common law & Ref & & & Ref & & \\
\hline Never married/separated/divorced or widowed & 1.6 & 1.2 & 2.3 & 1.5 & 1.1 & 2.1 \\
\hline \multicolumn{7}{|l|}{ Attended pregnancy support program } \\
\hline Yes & Ref & & & Ref & & \\
\hline No & 1.1 & 0.9 & 1.4 & 0.9 & 0.8 & 1.1 \\
\hline \multicolumn{7}{|l|}{ Attended parent support program } \\
\hline Yes & 1.3 & 1.1 & 1.6 & 1.2 & 1.0 & 1.5 \\
\hline No & Ref & & & Ref & & \\
\hline \multicolumn{7}{|c|}{ Availability of other types of support since birth of baby } \\
\hline All/most of the time & Ref & & & Ref & & \\
\hline Some/little/none of the time & 1.5 & 1.2 & 1.8 & 1.9 & 1.6 & 2.3 \\
\hline \multicolumn{7}{|l|}{ Sense of belonging to local community } \\
\hline Very strong/somewhat strong & Ref & & & Ref & & \\
\hline Somewhat weak/very weak & 2.1 & 1.7 & 2.5 & 2.4 & 2.0 & 2.8 \\
\hline \multicolumn{7}{|l|}{ History of depression or a mood disorder (ever) } \\
\hline Yes & 3.4 & 2.7 & 4.2 & 2.6 & 2.2 & 3.2 \\
\hline No & Ref & & & Ref & & \\
\hline \multicolumn{7}{|l|}{ Self-rated physical health } \\
\hline Excellent/very good & Ref & & & Ref & & \\
\hline Good/fair/poor & 2.0 & 1.7 & 2.4 & 2.4 & 2.0 & 2.9 \\
\hline
\end{tabular}

Bold values represent significant chi-square test with $p<0.05$

psychosocial strategies, such as peer support or nondirective counselling, and may include medication (Stewart and Vigod 2016). While the SMH did not assess the severity of illness, these recommendations may in part explain the choice in treatment observed in our study. Further, similar to in the general population, availability and accessibility of mental health care services may be a barrier to women receiving adequate care (Henderson et al. 2013).

\section{Maternal support and sense of belonging}

The SMH included several measures of maternal support and belonging. Only the availability of other types of support since the birth of the baby and a strong sense of belonging to local community were associated with lower odds of symptoms consistent with PPA and PPD. These findings are consistent with existing evidence which shows that the benefits of social support can be felt throughout the pregnancy and into motherhood, and may help prevent or mitigate PPD during the antepartum and postpartum period ( $\mathrm{Li}$ et al. 2017). In particular, a meta-analysis showed that women who were treated with psychosocial interventions were less likely to remain depressed at one-year postpartum than women who received standard postpartum primary care by a health care visitor, public health nurse, or primary care practitioner (Dennis and Hodnett 2007).

\section{Self-reported mental health, general health, and life satisfaction}

Women who had symptoms consistent with PPA or PPD were more concerned about their mental health, had poorer selfreported mental and physical health, and had a lower life satisfaction than those who did not have either condition. These symptoms are often indicative of poor mental health and 
should be monitored closely in order to identify the onset of illness (Yim et al. 2015; Wilkinson et al. 2017).

Following childbirth, nearly all women report experiencing physical discomfort or pain, primarily in the first eight weeks postpartum. Common symptoms include back pain, perineal pain, pain related to caesarean wound, breast pain, haemorrhoids, constipation, or incontinence (Cooklin et al. 2018). In the SMH, women were surveyed five to thirteen months postpartum, which allows women to recover following the delivery. Therefore, we can speculate that, to some extent, the higher proportion of women with symptoms consistent with PPD observed in this study who reported poor, fair, or good physical health may be a result of physical comorbidities or may reflect respondents including mental health in their global assessments of overall health. This association would benefit from further research.

\section{Limitations}

Due to the nature of the survey, the findings presented in this study are derived from brief screening tools for PPA and PPD, and do not reflect the number of cases of PPA or PPD diagnosed in Canada. In addition, women were surveyed five to thirteen months postpartum, during the winter months. Therefore, we could not examine how responses in the early postpartum months may vary from those six months or longer postpartum, and there could be seasonal effects. The questions asked to screen for symptoms consistent with PPA and PPD were assessed for different time intervals (i.e., symptoms of PPA were assessed over a two-week period, while symptoms of PPD were assessed over a seven-day period); therefore, the two estimates were not to be pooled in order to assess cooccurrence of symptoms. Information on non-respondents was not available, and as such, we cannot assess nonresponse bias. However, the final sample was weighted to be representative of the Canadian population of women who gave birth during the inclusion period. Finally, this study does not include women in Canada's territories, where PPA and PPD estimates may differ.

\section{Conclusion}

This study shows that a history of depression and self-reported physical health are most strongly associated with symptoms consistent with PPA or PPD, among the factors that we studied. Protective factors which were significantly associated with symptoms consistent with PPA or PPD were related to marital status and maternal support postpartum, such as the availability of other types of support programs, and a sense of belonging to local community. These findings stress the importance of having adequate maternal support postpartum as a means to support mental health in new mothers. Future studies should aim to determine how to optimize maternal support and to establish adequate timing of delivery of these supports in order to prevent illness.

Open Access This article is licensed under a Creative Commons Attribution 4.0 International License, which permits use, sharing, adaptation, distribution and reproduction in any medium or format, as long as you give appropriate credit to the original author(s) and the source, provide a link to the Creative Commons licence, and indicate if changes were made. The images or other third party material in this article are included in the article's Creative Commons licence, unless indicated otherwise in a credit line to the material. If material is not included in the article's Creative Commons licence and your intended use is not permitted by statutory regulation or exceeds the permitted use, you will need to obtain permission directly from the copyright holder. To view a copy of this licence, visit http://creativecommons.org/licenses/by/4.0/.

\section{References}

Brummelte, S., \& Galea, L. A. (2016). Postpartum depression: etiology, treatment and consequences for maternal care. Hormones and Behavior, 77, 153-166.

Centers for Disease Control. (2020). Content source: Division of Reproductive Health, National Center for Chronic Disease Prevention and Health Promotion. https://www.cdc.gov/ reproductivehealth/depression/index.htm/. Accessed 24 Jul 2020.

Cooklin, A. R., Amir, L. H., Nguyen, C. D., et al. (2018). Physical health, breastfeeding problems and maternal mood in the early postpartum: a prospective cohort study. Archives of Women's Mental Health, 21(3), 365-374.

Dennis, C. L., \& Hodnett, E. (2007). Psychosocial and psychological interventions for treating postpartum depression. Cochrane Database of Systematic Reviews, 2007, CD006116.

Duffy, B., Smith, K., Terhanian, G., et al. (2005). Comparing data from online and face-to-face surveys. International Journal of Market Research, 47(6), 615-639.

Eberhard-Gran, M., Eskild, A., Samuelsen, S. O., et al. (2007). A short matrix-version of the Edinburgh depression scale. Acta Psychiatrica Scandinavica, 116(3), 195-200.

Field, T. (2018). Postpartum anxiety prevalence, predictors and effects on child development: a review. Infant Behavior \& Development, 51, 24-32.

Henderson, C., Evans-Lacko, S., \& Thornicroft, G. (2013). Mental illness stigma, help seeking, and public health programs. American Journal of Public Health, 103(5), 777-780.

Iliadis, S. I., Skalkidou, A., Ranstrand, H., et al. (2018). Self-harm thoughts postpartum as a marker for long-term morbidity. Frontiers in Public Health. https://doi.org/10.3389/fpubh.2018. 00034.

Kroenke, K., Spitzer, R. L., et al. (2007). Anxiety disorders in primary care: prevalence, impairment, comorbidity, and detection. Annals of Internal Medicine, 146(5), 317-325.

Lanes, A., Kuk, J. L., \& Tamim, H. (2011). Prevalence and characteristics of postpartum depression symptomatology among Canadian women: a cross-sectional study. BMC Public Health. https://doi.org/10. 1186/1471-2458-11-302.

Li, Y., Long, Z., Cao, D., et al. (2017). Social support and depression across the perinatal period: a longitudinal study. Journal of Clinical Nursing, 26, 2776-2783. 
Milton, A. C., Ellis, L. A., Davenport, T. A., et al. (2017). Comparison of self-reported telephone interviewing and web-based survey responses: findings from the second Australian Young and Well National Survey. JMIR Mental Health. https://doi.org/10.2196/ mental.8222.

Nath, S., Ryan, E. G., Trevillion, K., et al. (2018). Prevalence and identification of anxiety disorders in pregnancy: the diagnostic accuracy of the two-item generalised anxiety disorder scale (GAD-2). BMJ Open. https://doi.org/10.1136/bmjopen-2018-023766.

O'Hara, M. W., \& Swain, A. M. (1996). Rates and risk of postpartum depression-a meta-analysis. International Review of Psychiatry, $8(1), 37-54$.

Pawluski, J. L., Lonstein, J. S., \& Fleming, A. S. (2017). The neurobiology of postpartum anxiety and depression. Trends in Neurosciences, 40(2), 106-120.

Public Health Agency of Canada. (2009). What Mothers Say: the Canadian Maternity Experiences Survey. Ottawa.

Ramakrishna, S., Cooklin, A. R., \& Leach, L. S. (2019). Comorbid anxiety and depression: a community-based study examining symptomology and correlates during the postpartum period. Journal of Reproductive and Infant Psychology, 37(5), 468-479.
Robertson, E., Grace, S., Wallington, T., \& Stewart, D. E. (2004). Antenatal risk factors for postpartum depression: a synthesis of recent literature. General Hospital Psychiatry, 26(4), 289-295.

Sharma, V., \& Sharma, P. (2012). Postpartum depression: diagnostic and treatment issues. Journal of Obstetrics and Gynaecology Canada, 34(5), 436-442.

Shoreya, S., Ing Chee, C. Y., \& Ng, E. D. (2018). Prevalence and incidence of postpartum depression among healthy mothers: a systematic review and meta-analysis. Journal of Psychiatric Research, 104, 235-248.

Stewart, D. E., \& Vigod, S. (2016). Postpartum depression. The New England Journal of Medicine, 375, 2177-2186.

Wilkinson, A., Anderson, S., \& Wheeler, S. B. (2017). Screening for and treating postpartum depression and psychosis: a cost-effectiveness analysis. Maternal and Child Health Journal, 21(4), 903-914.

Yim, I. S., Tanner Stapleton, L. R., Guardino, C. M., et al. (2015). Biological and psychosocial predictors of postpartum depression: systematic review and call for integration. Annual Review of Clinical Psychology, 11, 99-137.

Publisher's note Springer Nature remains neutral with regard to jurisdictional claims in published maps and institutional affiliations. 